\title{
CORTE INTERAMERICANA DE DIREITOS HUMANOS E A GARANTIA DE EMPREGO NO BRASIL
}

\author{
INTER-AMERICAN COURT OF HUMAN RIGHTS AND THE GUARANTEE OF \\ EMPLOYMENT IN BRAZIL
}

\section{Edilton Meireles de Oliveira Santos}

\begin{abstract}
Graduado em Direito pela Universidade Federal da Bahia (1985), mestrado em Direito pela Pontifícia Universidade Católica de São Paulo (2001), doutorado em Direito pela Pontifícia Universidade Católica de São Paulo (2003) e pós-doutoramento pela Faculdade de Direito da Universidade de Lisboa (2011). Atualmente é desembargador do trabalho no Tribunal Regional do Trabalho da $5^{a}$ Região, professor adjunto na graduação, mestrado e doutorado da Universidade Católica do Salvador (UCSal) e professor associado na graduação, mestrado e doutorado da Faculdade de Direito da Universidade Federal da Bahia (UFBa). E-mail: edilton_meireles@uol.com.br
\end{abstract}

Recebido em: 27/03/2019

Aprovado em: 16/04/2020

RESUMO: Neste trabalho é apresentado o resultado da pesquisa sobre o entendimento da Corte Interamericana de Direitos Humanos $(\mathrm{CIDH})$ sobre a garantia de emprego à luz da legislação comunitária e internacional. A pesquisa se justificou diante do conflito entre o entendimento que prevalece nos Tribunais brasileiros e a decisão da CIDH no caso Lagos del Campo vs. Peru. Analisando a decisão da CIDH e a legislação internacional aplicável, concluiu-se que a garantia do emprego, independentemente de qualquer regulamentação na legislação nacional, já é assegurada no Brasil. Analisou-se, ainda, a legislação brasileira a respeito da matéria e o efeito vinculante das decisões da CIDH em face dos Estados membros da OEA. Na pesquisa foi utilizado o método dedutivo, com revisão da literatura, interpretação de textos normativos e apreciação de decisões judiciais.

Palavras-chave: Garantia de emprego. Corte Interamericana. Precedente vinculante. Normas internacionais. Responsabilidade interna.

ABSTRACT: This paper presents the results of the research on the understanding of the Inter American Court of Human Rights (IACHR) on the guarantee of employment in light of community and international legislation. The research was justified by the conflict between the prevailing understanding in the Brazilian Courts and the decision of the IACHR in Lagos del Campo v. Peru. In analyzing the IACHR's decision and the applicable international law, it was concluded that the guarantee of employment, regardless of any regulation in the national legislation, is already assured in Brazil. The Brazilian legislation regarding the matter and the binding effect of the IACHR's decisions vis-a-vis the OAS member states were also analyzed. The research used the deductive method, with literature review, interpretation of normative texts and appreciation of judicial decisions.

Keywords: Job security. Inter-American Court. Precedent binding. International standards. Internal responsibility. 
SUMÁRIO: Introdução; 1. A decisão no caso Lagos del Campo vs. Peru; 2. Normas de proteção do direito ao trabalho; 3. Vinculação do precedente e responsabilidade do Estado brasileiro; Conclusões; Referências.

\section{INTRODUÇÃO}

É sabido que, transcorrido mais de 30 anos, o direito social fundamental de proteção contra a despedida arbitrária ou sem justa causa ainda não foi regulamentado pelo legislador infraconstitucional brasileiro.

Ainda hoje essa proteção, em texto normativo de origem brasileira, limita-se ao disposto de forma precária, inócua e ineficaz, no art. 10, inciso I, do Ato das Disposições Constitucionais Transitórias.

Em 2017, no entanto, ao julgar o caso Lagos del Campo vs. Peru, a Corte Interamericana de Direitos Humanos, pela via indireta, sacramentou o entendimento de que todos os trabalhadores da América são possuidores de garantia no emprego contra a despedida arbitrária ou sem justa causa.

Neste trabalho, portanto, procura-se apreciar essa decisão e seu efeito vinculante nas Cortes brasileiras, apontando-se os procedimentos que podem ser adotados para satisfação da garantia reconhecida pela Corte Interamericana.

Neste trabalho será utilizado o método dedutivo, com revisão da doutrina, análise da jurisprudência e interpretação de textos normativos.

\section{A DECISÃO NO CASO LAGOS DEL CAMPO VS. PERU}

Em decisão proferida em agosto de 2017, a Corte Interamericana de Direitos Humanos, ao apreciar demanda de proposta por Alfredo Lagos del Campo em face da República do Peru (OEA, 2017), acabou por reconhecer que diversos diplomas internacionais asseguram a garantia no emprego contra a despedida arbitrária, prevalecendo esse entendimento em toda a América. Diga-se que esta demanda proposta perante a Corte Interamericana decorreu do fato de o senhor Lagos del Campo não obter êxito perante a Justiça peruana.

$\mathrm{Na}$ oportunidade, na parte que nos interessa, a Corte Interamericana de Direitos Humanos (CIDH), ao decidir sobre a proteção ao emprego, concluiu que os direitos trabalhistas específicos protegidos pelo artigo 26 da Convenção Americana são derivados de padrões econômicos, sociais, educacionais, científicas e culturais contidos na Carta da OEA.

Lembrou que a Carta da OEA declara que "[o] trabalho é um direito e um dever social' e que deve ser ofertado "salários justos, oportunidades de emprego e condições de trabalho aceitável para todos" (OEA, 2017, tradução nossa).

Destacou que Os Estados-Membros têm entendido que a Declaração contém e define os direitos humanos fundamentais aos quais a Carta os define, de modo que não pode interpretar e aplicar a Carta da Organização sobre os direitos humanos, sem integrar normas relevantes com as disposições correspondentes da Declaração, como resultado da prática seguida pelos órgãos da OEA (tradução nossa).

Neste caminhar, a decisão lembra que

o artigo XIV da Declaração Americana estabelece que 'toda pessoa tem o direito de trabalhar em condições dignas e de seguir livremente sua vocação [...]'. Esta disposição é relevante para definir o alcance do artigo 26, dado que 'a Declaração Americana constitui, no pertinente e em relação à Carta da Organização, uma 
fonte de obrigações internacionais'. Além disso, o artigo 29.d da Convenção Americana prevê expressamente que '[n] ada na presente Convenção deve ser interpretado no sentido de: [...] d) excluir ou limitar o efeito que a Declaração Americana dos Direitos e Deveres do Homem e outros atos internacionais da mesma natureza (tradução nossa).

Cita que além do direito ao trabalho se extrair de uma interpretação do artigo 26 da Declaração em conjunto com a Carta da OEA, aquele é explicitamente reconhecido em várias leis internas dos Estados da região,

bem como um vasto corpus internacional iuris; inter alia: Artigo 6 do Pacto Internacional de Direitos Econômicos, Sociais e, o artigo 23 da Declaração Universal dos Direitos Humanos, artigos $7^{\circ}$ e $8^{\circ}$ da Carta Social das Américas, os artigos 6 e 7 do Protocolo Adicional da Convenção americana sobre Direitos Econômicos, Sociais e artigo 11 da Convenção sobre a Eliminação de Todas as Formas de Discriminação contra as Mulheres, o artigo 32.1 da Convenção sobre os Direitos da Criança, e do artigo 1 da Carta Social Europeia e Artigo 15 da Carta Africana dos Direitos Humanos e dos Povos (tradução nossa).

Da interpretação desses diversos textos internacionais e comunitários, a Corte Interamericana conclui que depreende obrigações do Estado em matéria de proteção do direito à segurança no emprego no setor privado, o que resulta, em princípio,

nas seguintes atribuições: a) tomar as medidas adequadas para o bom regulação e controle do referido direito; b) proteger o trabalhador, através de seus órgãos competentes, contra demissão injustificada; c) em caso de demissão injustificada, remediar a situação (seja através de reintegração ou, quando apropriado, através de compensação e outros benefícios previstos na legislação nacional). Assim, d) o Estado deve ter mecanismos de reclamação eficazes contra uma situação de despedimento sem justa causa, para garantir o acesso à justiça e à proteção judicial efetiva de tais direitos (tradução nossa).

Ressaltou, ainda, que "a segurança ao emprego não é uma estadia irrestrita no trabalho, mas a de respeitar esse direito, entre outras medidas, fornecendo garantias adequadas para proteger os trabalhadores" contra eventuais despedidas arbitrárias ou ilegais.

Ao final, a Corte Interamericana condenou a República peruana ao pagamento em favor do demandante a quantia de vinte mil dólares de indenização por danos morais e mais trinta mil dólares por danos materiais, por considerar que aquele Estado não assegurou a proteção garantida nos textos internacionais.

\section{NORMAS DE PROTEÇÃO DO DIREITO AO TRABALHO}

A decisão da Corte Interamericana reabre, no Brasil, a discussão quanto ao direito ao trabalho e a garantia contra a proteção contra despedida arbitrária e sem justa causa.

A Carta Magna brasileira de 1988 (BRASIL, 1988), ao menos em três passagens, faz menção à proteção do emprego. A primeira menção - talvez a mais importante - é encontrada no art. $6^{\circ}$, quando este dispõe que é direito social o trabalho. A segunda agasalha-se no inciso I do art. $7^{\circ}$ da Constituição, ao estabelecer a proteção contra despedida arbitrária ou sem justa causa, ainda que esta se resuma à mera indenização compensatória. Por fim, a encontramos no art. 170 da CF, quando este inclui, dentre os princípios que regem a nossa Ordem Econômica, a busca do pleno emprego (inciso VIII). 
Observe-se, de logo, que a Constituição brasileira possui expressa disposição assegurando o direito ao trabalho (art. $6^{\circ}$ ), assim como a portuguesa (art. 58, 1) (PORTUGAL, 1976), a espanhola (art. 35.1) (ESPANHA, 1978) e a italiana (art. 4º) (ITÁLIA, 1948). Além disso, do princípio do pleno emprego se extrai essa vantagem ou mesmo no princípio do Estado Social como sustentado na Alemanha, pois implícito a ela a luta pela realização do valor trabalho (SASTRE, 1996, p. 71). Isso porque, quando se busca garantir o pleno emprego, por óbvio, está-se a assegurar o direito ao trabalho subordinado, até porque aquele só se realiza por meio deste.

Óbvio, ainda, que quando se estabelece que o trabalho é um direito social, se quer afirmar que todos têm direito ao trabalho (MAZZIOTTI, 1956, p. 56-86). Ele, aliás, é o primeiro dos direitos sociais (GIUBBONI, 2006, p. 5) e, ao certo, o mais controvertido e ambíguo. E a essa conclusão - quanto à existência do direito ao trabalho - se pode chegar também a partir da conjugação de diversas regras constitucionais que buscam assegurar ou proteger o emprego.

O direito ao trabalho se retira, por exemplo, das regras constitucionais que estabelecem uma política de formação e readaptação profissional, como a do art. 203 da Constituição brasileira, que preceitua que a assistência social tem por objetivos "a promoção da integração ao mercado de trabalho" (inciso III). Da mesma forma, esse direito é alcançado a partir da regra que fixa que a educação "será promovida e incentivada com a colaboração da sociedade, visando ao pleno desenvolvimento da pessoa, seu preparo para o exercício da cidadania e sua qualificação para o trabalho" (art. 205), devendo a lei estabelecer o plano nacional de educação "visando à articulação e ao desenvolvimento do ensino em seus diversos níveis e à integração das ações do Poder Público que conduzam à... formação para o trabalho" (art. 214, IV).

O mesmo se pode afirmar, em área mais específica, quando estabelece que "o Estado apoiará a formação de recursos humanos nas áreas de ciência, pesquisa e tecnologia, e concederá aos que delas se ocupem meios e condições especiais de trabalho" (art. $218, \S 3^{\circ}$ ). Além disso, cabe lembrar que "é dever da família, da sociedade e do Estado assegurar à criança, ao adolescente e ao jovem, com absoluta prioridade, o direito... à profissionalização...” (art. 227).

Nesta mesma trilha, cabe citar as regras que apontam para uma política de desenvolvimento e da "redução das desigualdades regionais e sociais" (art. 170, VII), a fim de assegurar a todos existência digna conforme os ditames da justiça social (caput, art. 170), lembrando que tais pretensões se revelam como objetivos fundamentais do Brasil (art. $3^{\circ}$, incisos III e IV). Ora, numa sociedade capitalista, a desigualdade social se combate através da distribuição de renda e esta se obtém através do trabalho. Logo, o trabalho se constitui um direito inerente ao Estado Social.

Pode-se lembrar, ainda, das regras que estabelecem uma especial atenção a grupos sociais que encontram dificuldade para obter emprego ou que podem sofrer discriminação. E aqui, então, lembramos da regra que assegura a licença à gestante, sem prejuízo do emprego e do salário (art. $\left.7^{\circ}, \mathrm{XVIII}\right)$, a proteção do mercado de trabalho da mulher, mediante incentivos específicos (art. $7^{\circ}$, XX), a proteção em face da automação (art. $7^{\circ}, \mathrm{XXVII}$ ) e a proibição de qualquer discriminação no tocante a salário e critérios de admissão do trabalhador portador de deficiência (art. $7^{\circ}, \mathrm{XXXI}$ ).

Óbvio, ainda, que o direito ao trabalho resta patente nas regras que estabelecem a proteção do emprego, tais como a que veda a despedida arbitrária ou sem justa causa (art. $7^{\circ}, \mathrm{I}$ ), quando se combate "a dispensa do empregado sindicalizado a partir do registro da candidatura a cargo de direção ou representação sindical e, se eleito, ainda que suplente, até um ano após o final do mandato, salvo se cometer falta grave nos termos da lei" (art. $8^{\circ}$, inciso VIII) ou, ainda, quando assegura o emprego às gestantes e aos membros da CIPA (art. 19 do ADCT).

$\mathrm{Na}$ área pública, cabe lembrar o direito público de acesso ao serviço público (art. 37, I e II) e o da estabilidade (art. 34).

Não fosse todo esse conjunto de normas contidas na Constituição brasileira, que configuram o verdadeiro direito de cidadania ao trabalho (LANDA, 2000, p. 163), essa mesma garantia encontra-se consagrada em diversos textos internacionais, os quais o Brasil já ratificou, 
aprovou ou aderiu, o que reforça a conclusão acima quanto ter sido essa vantagem (direito ao trabalho) agasalhada no tex to constitucional brasileiro.

Assim é que o direito ao trabalho resta inserto na Declaração Universal dos Direitos Humanos da ONU, de 1948, quando, expressamente, em seu art. 23, item 1, afirma que "toda pessoa tem direito ao trabalho, à livre escolha do trabalho, a condições equitativas e satisfatórias de trabalho e à proteção contra o desemprego" (ONU, 1948).

Esse mesmo direito foi assegurado no Pacto Internacional dos Direitos Econômicos, Sociais e Culturais, em seu art. 60-1, ao estabelecer que "os estados-partes no presente Pacto reconhecem o direito de toda pessoa de ter a possibilidade de ganhar a vida mediante um trabalho livremente escolhido ou aceito e tomarão medidas apropriadas para salvaguardar esse direito", devendo, conforme item 2 desse mesmo dispositivo, que cada Estado-parte,

a fim de assegurar o pleno exercício desse direito, deverá incluir a orientação e a formação técnica e profissional, a elaboração de programas, normas técnicas apropriadas para assegurar um desenvolvimento econômico, social e cultural constante e o pleno emprego produtivo em condições que salvaguardem aos indivíduos o gozo das liberdades políticas e econômicas fundamentais (ONU, 1966).

No seio da ONU encontramos, ainda, a Declaração sobre o Direito ao Desenvolvimento, adotada pela Revolução n. 41/128 da Assembleia Geral das Nações Unidas, de 4 de dezembro de 1986, na qual ficou estabelecido, em seu art. $8^{\circ}, \S 1^{\circ}$, que

os Estados devem tomar, em nível nacional, todas as medidas necessárias para a realização do direito ao desenvolvimento, e devem assegurar, inter alia, igualdade de oportunidade para todos no acesso aos recursos básicos, educação, serviços de saúde, alimentação, habitação, emprego e distribuição equitativa da renda...(ONU, 1986).

Igual direito foi firmado na Declaração sobre o Progresso e o Desenvolvimento Social da ONU, proclamada pela Assembleia Geral, em sua Resolução n. 2.542 (XXIV), de 11.12.1969, quando ficou esclarecido, em seu art. $6^{\circ}$, que o "desenvolvimento social exige que se garanta a toda pessoa o direito a trabalhar e a eleger o emprego livremente" (ONU, 1969).

Isso porque, conforme esse mesmo preceito, em sua segunda parte, "o progresso e o desenvolvimento social exigem a participação de todos os mesmos da sociedade em um trabalho produtivo e socialmente útil, e o estabelecimento, em conformidade com os direitos humanos e as liberdades fundamentais, assim como com os princípios da justiça e da função social da propriedade, de modos de propriedade da terra e dos médios de produção que excluam quaisquer formas de exploração do homem, garantem igual direito à propriedade para todos, e criem entre os homens condições que levem a sua autêntica igualdade".

Cabe citar, ainda, a Resolução n. 34/46 da ONU de 1979, que, em seu item 7, pontifica que "a fim de garantir cabalmente os direitos humanos e a plena dignidade pessoal, é necessário garantir o direito ao trabalho..." (ONU, 1979).

Neste sentido, ainda, devemos lembrar do Preâmbulo da Constituição da OIT, que menciona ser um de seus objetivos "a luta contra o desemprego" (OIT, 1946). Daí porque constar na Declaração da Filadélfia de 1944, em seu item III, que a Conferência

reconhece a obrigação solene de a Organização Internacional do Trabalho secundar execução, entre as diferentes nações do mundo, de programas próprios à realização: a) do pleno emprego e da elevação do nível de vida; e b) do emprego dos trabalhadores em ocupações nas quais tenham a satisfação de aplicar toda a 
sua habilidade e os seus conhecimentos e de contribuir da melhor forma para o bem-estar comum (OIT, 1944).

No âmbito, ainda, da OIT, cabe citar a Convenção n. 122, de 9 de julho de 1964, que trata da Política de Emprego, a qual preceitua, em seu art. $1^{\circ}, \S 1^{\circ}$, que

com o objetivo de estimular o crescimento e o desenvolvimento econômico, de elevar os níveis de vida, de atender às necessidades de mão de obra e de resolver o problema do desemprego e do subemprego, todo membro formulará e aplicará, como um objetivo essencial, uma política ativa visando promover o pleno emprego, produtivo e livremente escolhido (1998a).

Esse mesmo direito voltou a ser reafirmado através da Convenção n. 168 da OIT, que cuida da Promoção do Emprego e Proteção Contra o Desemprego (OIT, 1998a). Por esta ficou estabelecido, em seu art. $2^{\circ}$, que

todo membro deverá adotar medidas apropriadas para coordenar o seu regime de proteção contra o desemprego e a sua política de emprego. Para esse fim, deverá providenciar que o seu sistema de proteção contra o desemprego e, em particular, as modalidades de indenização do desemprego, contribuam para a promoção do pleno emprego produtivo, livremente escolhido, e que não tenham como resultado dissuadir os empregadores de oferecerem emprego produtivo, nem os trabalhadores de procurá-lo (OIT, 1998a).

Estabeleceu-se, ainda, em seu art. $7^{\circ}$ que

todo membro deverá formular, como objetivo prioritário, uma política destinada a promover o pleno emprego, produtivo e livremente escolhido, por todos os meios adequados, inclusive a seguridade social. Esses meios deverão incluir, entre outros, os serviços do emprego e a formação e orientação profissionais (OIT, 1998a).

Outrossim, resta imposta a adoção de políticas de ações afirmativas, com

medidas especiais para fomentar possibilidades suplementares de emprego e a ajuda ao emprego, bem como para facilitar o emprego produtivo e livremente escolhido de determinadas categorias de pessoas desfavorecidas que tenham ou possam ter dificuldades para encontrar emprego duradouro, como as mulheres, os trabalhadores jovens, os deficientes físicos, os trabalhadores de idade avançada, os desempregados durante um período longo, os trabalhadores migrantes em situação regular e os trabalhadores afetados por reestruturações (art. $8^{\circ}$ ) (OIT, 1998a).

\section{Daí se poder sustentar com Vezio Crisafulli que}

a afirmação do direito ao trabalho representa, de fato, também historicamente, um ponto culminante da tendência intervencionista em matéria econômico-social, destinada a realizar as condições essenciais de segurança para todos os cidadãos, que é um dos componentes essenciais da fórmula política posta na base..." do Estado social. É um "princípio de estrutura (1952, p. 151, tradução nossa).

O direito ao trabalho, em verdade, constitui, em última instância, verdadeiro direito de participação política. "Um direito sem o qual somos privados não só dos benefícios privados (do 
direito aos meios de subsistência), mas substancialmente também da nossa personalidade social, da liberdade e da cidadania" (CANTARO, 2006, p. 79-80, tradução nossa).

Tudo isso, pois, conduz a concluir que o direito ao trabalho e o princípio do pleno emprego revelam a existência de um verdadeiro princípio de proteção do emprego a reger as relações de emprego no Brasil. E da cláusula que estabelece ser um direito social o trabalho (ou o direito ao trabalho) se extrai, pelo menos, três teses interpretativas.

A primeira delas seria aquela que estabelece que a norma do art. $6^{\circ}$ da Constituição, ao se referir ao direito ao trabalho, apenas encerra uma cláusula programática, mais de sentido ético político do que político-jurídico. Seria uma mera orientação ao legislador. Uma norma de direito condicional, do tipo finalístico, dada a sua "impraticabilidade" (BAYLOS GRAU, 2005, p. 256) ou uma "voz vazia de conteúdo normativo" (BAYLOS, 2005a, p. 20, tradução nossa). Isso porque o emprego estaria sujeito a um princípio fundamental da organização da sociedade e do mercado de trabalho que consistiria na livre-iniciativa e na liberdade de empresa, o que impediria que se assegurasse a todos um trabalho ((BAYLOS, 2005a, p. 20).

Esse entendimento, no entanto, deve ser rejeitado, já que, no mínimo, essa regra irradia eficácia sobre o legislador, que fica vedado de agir em sentido contrário ao direito ao trabalho.

A segunda posição possível de ser adotada é a que sustenta que a Constituição assegurou o direito subjetivo de toda pessoa obter um emprego, seja perante o Poder Público, seja em face do particular, numa irradiação dos direitos fundamentais perante todos.

Essa posição, no entanto, somente seria aceitável numa sociedade comunista. Isso porque, em um sistema capitalista, como o adotado pelo Brasil, não se mostra, no mínimo, razoável se sustentar essa posição (ARCOS RAMÍREZ, 2000). E vários argumentos podem ser apontados, dentre eles a existência da liberdade de empresa, que impediria que o Estado obrigasse os empregadores a contratar empregados ${ }^{1}$, violando-se, não só o direito de liberdade, como o desenvolvimento da personalidade do empresário, além de colidir com o poder de decisão deste no seio da empresa. Acrescente-se, ainda, que essa imposição poderia levar à bancarrota da própria empresa (SASTRE, 1996, p. 100), atingindo-se, assim, o próprio direito à livre-iniciativa.

Uma lei impondo a obrigação de contratar empregados, assim, incorreria no vício da inconstitucionalidade (MONTOYA MELGAR, 1979, p. 333), tal como já declarou a Corte Constitucional da Itália, em face do Decreto-Lei de 16.9.47, de n. 929, ratificado pela Lei de 17 de maio de 1952, de n. 621, que impunha a admissão compulsória de trabalhadores no setor agrícola (ITÁLIA, 1958; MANCINI, 1975, p. 199-276). É claro, no entanto, que essa regra de não contratação obrigatória pode ser mitigada em casos excepcionais, especialmente quando se busca a realização substancial do direito à igualdade. Daí porque ser legítima a lei, por exemplo, que impõe a contratação de pessoas portadoras de necessidades especiais.

É óbvio que, numa sociedade capitalista,

o ordenamento do Estado não pode assegurar um emprego a cada trabalhador pela simples razão de que a oferta de trabalho reside majoritariamente nos sujeitos privados, cuja decisão de criação de emprego é finalmente livre e não vem determinada, senão impulsionada ou fomentada por ações dos poderes públicos. O direito ao trabalho efetivo poderia ser garantido de modo pleno e sem requisitos tão só, por hipóteses, se sustentado numa organização econômica em que o próprio Estado que proclama o direito subjetivo for ao mesmo tempo titular da estrutura ocupacional do país ou, ao menos, estiver em condições de decidir em seu conjunto e de modo significativo à criação de emprego. Em não sendo assim, já que se reconhece a liberdade de empresa como marco da

\footnotetext{
${ }^{1}$ Sem excluir a possibilidade dessa obrigação em alguns casos concretos, especialmente para proteção de grupos sociais portadores de necessidades especiais.
}

Revista de Direito Brasileira | Florianópolis, SC | v. 24 | n. 9 | p.378-395 | Set./Dez. 2019 
economia de mercado, o conteúdo do direito ao trabalho há de ter necessariamente uma significação diferente (PALOMEQUE LOPEZ, 1996, p. 15, tradução nossa).

Isso, porém, não significa em concluir que a simples formulação da cláusula da busca do pleno emprego ou do direito social ao trabalho tenha um caráter meramente retórico, programático ou pedagógico. Na realidade, o mandamento constitucional da busca do pleno emprego ou do direito social do trabalho, no mínimo, vincula o Poder Público, que resta comprometido formal e solenemente com a consecução dessa finalidade (PROSPERETTI, 1970, p. 364).

E aqui cabe acrescer, ainda, argumentos que conduzem à aceitação do princípio do direito ao trabalho. O primeiro deles é que é universalmente aceita como constitucional a legislação infraconstitucional que assegura, em percentuais limitados, a contratação obrigatória de trabalhadores integrantes de categorias que merecem uma maior proteção, a exemplo dos portadores de necessidades e aprendizes (ALARCÓN CARACUEL, 1979, p. 23). Aceita, assim, essa legislação, tem-se como válido o princípio do direito ao trabalho e sua compatibilidade com o sistema constitucional brasileiro. Isso porque, quando se obriga a contratação desses trabalhadores mais débeis, em outras palavras, está-se dando cumprimento à literalidade do direito ao trabalho.

Não fosse isso, é preciso lembrar que o direito social ao trabalho (art. $6^{\circ}$ da CF) deve ser interpretado com o art. 170 da Carta Magna (BRASIL, 1988). E este, como reiteradamente já dito, inclui dentre os princípios da Ordem Econômica a busca do pleno emprego. Daí se tem, então, que esse princípio da Ordem Econômica abre brecha para que o legislador possa, observado o princípio da razoabilidade, estabelecer restrições à liberdade do empresário (ao direito de empresa ou à livreiniciativa).

Aliás, é preciso lembrar que a Constituição Federal fala em valores sociais do trabalho e da livre-iniciativa. Logo, a livre-iniciativa somente pode ser exercida se cumprir uma função social (CORVAL, 2006). Pode, então, o legislador estabelecer normas que limitam o direito à livreiniciativa, até porque ele também não é absoluto, ordenando, por exemplo, a contratação obrigatória de empregados, desde que observado o princípio da razoabilidade. Cumpriria, aqui, a livre-iniciativa sua função social, enquanto fundamento de nossa República (inciso IV do art. $1^{\circ}$ da CF) (BRASIL, 1988).

E aqui surge, então, a terceira posição possível de ser adotada em face do direito social ao trabalho. É aquela que entende que essa cláusula implica em verdadeira obrigação jurídica para os Poderes Públicos, inclusive o Poder Judiciário. Mas o princípio da busca do pleno emprego e do direito ao trabalho não vincula apenas o Poder Público. Isso porque a Constituição elegeu aquele primeiro princípio (pleno emprego) como integrante da Ordem Econômica, e como esta se funda na livre-iniciativa e na valorização do trabalho humano, por certo que ele se volta, também, ao particular. Ou seja, esse princípio não só vincula o Poder Público, como obriga o particular que exerce a atividade econômica.

Neste ponto, então, resta fixado que o direito ao trabalho, no âmbito subjetivo do direito, tem como sujeitos passivos o Estado e o particular. Já no âmbito ativo, essa regra se volta em favor de todos os que precisam do trabalho para uma vida digna, seja brasileiro ou residente no país, sem qualquer distinção.

Cabe, no entanto, extrair da regra do direito social ao trabalho e do princípio do pleno emprego seu alcance, buscando-se, assim, sua eficácia jurídica e seu conteúdo, ainda que este último seja alternativo à literalidade do seu texto (direito a um posto de trabalho).

Neste sentido, então, pode-se, desde logo, mencionar que o direito ao trabalho impõe uma condição hermenêutica, pois estabelece um valor interpretativo do ordenamento, a vedar, inclusive, normas que não se voltem à garantia do direito ao trabalho, por exemplo. Aqui teríamos, assim, uma primeira eficácia do mandamento constitucional em epígrafe. 
Obriga, assim, no mínimo, ao Poder Judiciário, que se vê impelido a interpretar as normas de modo a fazer valer esse princípio constitucional de busca do pleno emprego e a garantir o direito social do trabalho, em prol do próprio sistema capitalista, lembrando que, historicamente, o direito ao trabalho foi o primeiro direito social a ser reivindicado (SASTRE, 1996, p. 23). Fica, assim, o Poder Judiciário obrigado a interpretar as normas no sentido mais favorável para satisfação da pretensão ao trabalho, afastando-se de entendimentos que possam conduzir à não aplicação desse direito constitucional (SASTRE, 1996, p. 23).

Contudo, não só essa eficácia interpretativa. Das regras constitucionais pertinentes também se extraem obrigações prestacionais por parte do Estado. Isso porque ele obriga o legislador a estabelecer uma legislação voltada à busca e manutenção do pleno emprego e da garantia do direito ao trabalho. Essa garantia, assim, justifica a edição de lei ordinária garantindo a estabilidade no emprego, ainda que em casos excepcionais (BRASIL, 2005). Porém, não só fazer uma legislação ocupacionista, como também a se abster de não fazer, isto é, de não revogar as normas que já existem e que são regras que suscitam ou facilitam a ocupação do trabalhador, sem, ao menos, sub-rogá-las por outras que têm a mesma finalidade (MORTATI, 2005, p. 26), observando o princípio do não retrocesso.

Obriga, ainda, esse mesmo princípio, o Administrador a adotar políticas públicas contra o desemprego, de amparo ao desempregado e, antes, de incentivo ao emprego, seja através de medidas para sua aquisição, seja para a sua manutenção (BAUGARD, 2014, p. 333). Interessante mencionar que a Corte Constitucional espanhola teve como constitucional lei infraconstitucional que estabelece a possibilidade de aposentadoria compulsória por idade - em contradição ao direito ao trabalho - quando esta se insere numa política de pleno emprego, assegurando a outro grupo social o posto de trabalho, desde que ao aposentado esteja assegurado benefícios previdenciários para seu sustento (ESPANHA, 1981; SOUZA, 2012), isso sem falar em políticas de formação, qualificação (GIUBBONI, 2006, p. 13) e readaptação profissional.

Observe-se, ainda, que, a partir dessa obrigação estatal de zelar pelo pleno emprego, podese incluir o seguro-desemprego como vantagem decorrente da mesma. Isso porque esse benefício pago pelo Estado apresenta-se como verdadeiro seguro para a hipótese em que o Poder Público não gera emprego para todos. Isso é, quando o Estado se revela inadimplente em sua obrigação de garantir emprego para todos (pleno emprego), ele fica obrigado a pagar uma indenização (o segurodesemprego) ao credor-desempregado involuntariamente, titular do direito ao trabalho. É uma espécie de compensação "pela não satisfação do direito ao trabalho" (ABRANTES, 1990, p. 36).

Como, entretanto, o princípio do pleno emprego sujeita a ordem econômica, é certo, ainda, que este rege os atos dos particulares, de modo que as empresas devem, também, adotar práticas voltadas para a criação de empregos e para sua manutenção, além de contribuírem para a formação, qualificação (SASTRE, 1996, p. 123) e readaptação profissional (ALARCÓN CARACUEL, 1979, p. 32). Fica obrigado, assim, o particular a agir, no campo de sua área produtiva (livre-iniciativa), de modo não arbitrário em relação à ocupação, seja no sentido de ofertar, como no de manter o posto de trabalho, salvo razões objetivamente apreciáveis (MORTATI, 2005, p. 27).

É certo, no entanto, que, na satisfação desse princípio-regra (direito ao trabalho), não se exige a implantação de um modelo econômico de planificação. Contudo, a partir das características do sistema capitalista, o direito ao trabalho entra em conflito com outros direitos constitucionais e, consequentemente, se verá diante de certas limitações, o que, aliás, ocorre igualmente com outros direitos fundamentais. O que se impõe, então, é resolver esses conflitos a partir da aplicação do princípio da proporcionalidade.

Costantino Mortati ensina, por sua vez, que se pode classificar as intervenções, para satisfação desse princípio, especialmente na sua vertente da busca do pleno emprego, em quatro grupos de intervenções: a) de promoção da capacidade técnica do trabalhador; b) da promoção menos onerosa da ocupação; c) da imposição de determinadas quotas de contratação; e d) da estabilização das relações de trabalho (MORTATI, 2005, p. 30-31). 
No primeiro grupo, encontram-se todas as ações que devem ser efetivadas para maior qualificação do trabalhador de modo a lhe facilitar o quanto mais rápido possível a ocupação. Mas não só de forma mais rápida, como de modo mais profícuo para a própria sociedade.

No segundo grupo se enquadra todas as ações e políticas públicas que devem ser desenvolvidas no sentido de facilitar, de forma menos onerosa, a oferta do trabalho, seja com a redução de tributos, seja por meio de incentivos fiscais etc.

Com base no terceiro grupo, o princípio do direito ao trabalho, como já dito, justifica a adoção de quotas de contratação de determinados trabalhadores, especialmente aqueles que se inserem em grupos sociais menos privilegiados ou discriminados.

Por fim, no quarto grupo inserem-se todas as ações, políticas e diplomas legais que impõem a estabilidade no emprego ou que, de alguma forma, limitam a despedida arbitrária ou incentivam a manutenção do emprego; no Brasil, entretanto, a imposição da estabilidade sobre o condicionamento posto no inciso I do art. $7^{\circ}$ da $\mathrm{CF}$, sem que com isso se esteja vedado o avanço social, ainda que por norma infraconstitucional.

Na Espanha, todavia, já se decidiu que, em seu aspecto individual, o

direito ao trabalho não se esgota na liberdade de trabalhar; supõe também o direito a um posto de e, como tal, tem um duplo aspecto: individual e coletivo, ambos reconhecidos nos arts. 35.1 e 40.1 da nossa Constituição, respectivamente. Em seu aspecto individual, se concretiza em igual direito igual a todos a um determinado posto de trabalho se se cumprem os requisitos de capacitação necessários e no direito à continuidade ou estabilidade no emprego, ou seja, não ser demitido se não existe uma causa justa (ESPANHA, 1981, tradução nossa).

É preciso, ainda, lembrar que o direito ao trabalho está vinculado intimamente com o princípio da dignidade da pessoa, pois, em regra, somente através dele o homem desenvolve sua personalidade. Pode-se, ainda, relacioná-lo com o próprio direito à vida, pois para grande maioria da população é através do trabalho que se obtém os meios necessários à subsistência (ALARCÓN, 1979, p. 31).

Desse modo, chega-se à conclusão de que o princípio-regra do direito ao trabalho ou ao pleno emprego é muito mais do que uma simples declaração retórica ou programática. Dela se extrai, portanto, pelo menos, quatro obrigações básicas, quais sejam: proteção contra o desemprego involuntário, promoção do emprego, limitação da despedida e a implementação de programas de orientação e formação profissional.

Cabe ressaltar, porém, que, tendo em vista o "estatuto constitucional de cidadania social", ainda que a política do pleno emprego se volte, num primeiro plano, para proteção do trabalho assalariado, isso não afasta a implantação de programas que visem valorizar o trabalho em sentido amplo. Isto é, cabe também a implantação de políticas de proteção de outros tipos de trabalho ou atividades, surgidos com esta ou aquela "roupagem jurídica", mas que, no fundo, estão açambarcados pela proteção constitucional do mais débil ou com vista a valorizar e incentivar a contribuição do indivíduo para realização do Estado Social por meio do seu labor (enquanto componente da riqueza nacional), ainda que autônomo (LANDA, 2000, p. 166).

Sem querer, no entanto, alongar esse outro debate, neste ponto cabe delimitar o conteúdo do princípio do direito ao trabalho considerando três momentos distintos da relação de emprego: da constituição da relação de emprego, do desenvolvimento dessa relação e da extinção do contrato respectivo. Dado o recorte desta pesquisa, no entanto, cumpre destacar o último desses momentos de proteção.

$\mathrm{Na}$ fase de extinção do contrato de emprego, o princípio do direito ao trabalho se mostra por demais relevante. Isso porque não basta assegurar o direito de acesso ao posto de trabalho. Do direito ao trabalho também decorre o direito de manutenção do emprego, procurando-se, assim, a 
satisfação do pleno emprego. O principal instituto daí decorrente é o da estabilidade no emprego ou da garantia de emprego.

O direito do trabalho, assim, respalda toda legislação infraconstitucional que, fundada em motivos razoáveis, estabelece outras hipóteses de estabilidade além daquelas já mencionadas na Carta Magna.

Outrossim, sob o manto do princípio do direito ao trabalho e da proteção contra despedida arbitrária se pode estabelecer uma legislação que preceitue um nexo de causalidade (motivação) para o rompimento contratual, ainda que se faça a opção pelo pagamento de indenização compensatória quando a extinção do contrato se faça por denúncia vazia (despedida imotivada). Do princípio ao emprego, portanto, também decorre o direito à justificação ao rompimento contratual, isto é, o empregador tem o dever, a princípio de indicar o motivo para a despedida do trabalhador (BAUGARD, 2014, p. 336).

Esse princípio, no entanto, não torna inconstitucional a regra que impõe a aposentadoria compulsória do empregado a pedido do empregador (art. 51 da Lei n. 8.213/91) (BRASIL, 1991), desde que mantido o posto de trabalho. Poder-se-ia, inicialmente, pensar que essa regra viola o direito ao trabalho, já que justamente conduz o trabalhador ao desemprego. Contudo, conforme entendimento já respaldado pela Corte Constitucional espanhola, considerando ainda o princípio do pleno emprego, mostra-se razoável esse dispositivo por ele se inserir numa política de geração de emprego, configurada na repartição ou redistribuição do trabalho, supondo-se a limitação do direito ao trabalho a um grupo para garantir o mesmo direito a outro grupo. "Através dele se limita temporalmente ao primeiro o exercício do direito individual ao trabalho mediante a fixação de um período máximo em que esse direito pode ser exercido, com a finalidade de fazer possível ao segundo o exercício desse mesmo direito" (ESPANHA, 1981).

Contudo, para assim se concluir, é necessário se ter que a aposentadoria compulsória não implica em nenhum caso na supressão do posto de trabalho; do contrário, atentaria aos princípios do direito ao trabalho e do pleno emprego (SASTRE, 1996, p. 132). Desse modo, a conduta do empregador em requerer a aposentadoria compulsória do empregado só se justifica constitucionalmente se for mantido o posto de trabalho, com a contratação de outro trabalhador para ocupá-lo. E neste caso, podemos pensar que o início da aposentadoria apenas se dará a partir do momento em que o novo trabalhador for admitido (SOUZA, 2012).

Essas medidas, pois, dão contornos ao princípio de proteção ao emprego, lembrando que dele não implica que o Estado deva obrigatoriamente proporcionar trabalho a toda pessoa que o deseja, mas, sim, de fazer tudo que está a seu alcance para este objetivo e, quando não alcançado, garantir a proteção contra o desemprego involuntário. E do particular o que se exige é que adote uma conduta em favor do trabalho e do pleno emprego, no mínimo, abstraindo-se de atos que possam conduzir a um caminho oposto.

\section{VINCULAÇÃO DO PRECEDENTE E RESPONSABILIDADE DO ESTADO BRASILEIRO.}

A partir do exposto no item anterior se pode concluir facilmente que cabe ao Judiciário brasileiro assegurar a proteção do direito ao trabalho, afastando qualquer conduta que torne eficaz a despedida arbitrária ou sem justa causa.

Não fosse todo o arcabouço jurídico mencionado que respaldaria a decisão judicial voltada a proteger o emprego quando diante da despedida arbitrária ou sem justa causa, tem-se, agora, diante do decidido pela Corte Interamericana de Direitos Humanos, a obrigação ao devido respeito a este precedente, que, na prática se torna vinculante.

Para concluir que esse precedente é vinculante ao Estado-juiz brasileiro é preciso lembrar

que, quando não observadas as decisões da Corte Interamericana, os Estados membros da 
Organização dos Estados Americanos podem vir a ser condenados a indenizar aqueles que tiveram seus direitos não reconhecidos no plano interno de cada Estado.

Foi o que ocorreu no caso Lagos del Campos e a República do Peru. Neste caso, o Judiciário peruano não assegurou a proteção ao emprego do trabalhador Lagos del Campos. Este, então, processou o Estado peruano perante a Corte Interamericana, que, por sua vez, reconhecendo o descumprimento da legislação internacional pertinente, condenou a República peruana a indenizar o demandante, diante da violação do seu direito de proteção ao emprego por parte do Estado.

Dessa decisão se tem que, sempre que o Estado membro não cumpre a norma internacional (ou viola os precedentes da Corte), ele estará sujeito a uma condenação reparadora da lesão causada à pessoa cujo direito não foi reconhecido no plano interno do país. Ou seja, diante do precedente Lagos del Campos, ou o Estado membro (inclusive seu Poder Judiciário) reconhece a proteção ao emprego, impondo que o empregador reintegre ou indenize o trabalhador despedido arbitrariamente ou sem justa causa, ou o próprio Estado membro poderá ser condenado numa indenização correspondente ao dano sofrido pelo trabalhador. Em outras palavras: ou o empregador responde pelos seus atos, ou o Estado brasileiro pode ser responsabilizado por sua decisão em não condenar o empregador. O Estado nacional, pois, responde pela violação da norma internacional (HITTERS, 2007, p. 203-222).

O trabalhador prejudicado, porém, somente poderá demandar o Estado brasileiro após esgotar todos os recursos internos possíveis para reconhecimento de seu direito de proteção ao emprego (FEIJÓ, 2014), cabendo ao Estado membro comprovar o seu não esgotamento (OEA, 2006).

Uma vez eventualmente condenado o Estado brasileiro, a decisão da Corte Interamericana de Direitos Humanos pode ser executada perante o Judiciário brasileiro (RESENDE, 2013. p. 226236) por força da aplicação do art. 68 da Convenção Americana sobre Direitos Humanos, que dispõe que "Os Estados Partes na Convenção comprometem-se a cumprir a decisão da Corte em todo caso em que forem partes" e que "A parte da sentença que determinar indenização compensatória poderá ser executada no país respectivo pelo processo interno vigente para a execução de sentenças contra o Estado" (OEA, 1969; SANT'ANA, 2002, p. 253-276; SALVADOR, 2006, p. 643-665).

No caso dessa condenação, o trabalhador poderá executar a sentença da Corte Interamericana, sem necessidade de sua prévia homologação (SANT'ANA, 2002, p. 260-263), perante a Justiça Federal. Não se trata de demanda de competência da Justiça do Trabalho, já que a execução se faz pelo trabalhador em face da conduta do Estado brasileiro, decorrente de litígio entre o país e seu residente.

Esse entendimento acima, por sua vez, já foi esposado pela própria Corte Interamericana de Direitos Humanos ao apreciar o caso Almonacid versus Chile. Na oportunidade, a Corte Interamericana conclui que, verbis:

124. A Corte está ciente de que os juízes e os tribunais estão sujeitos ao império da lei e, portanto, são obrigados a aplicar as disposições vigentes no ordenamento jurídico. Mas quando um Estado ratifica um tratado internacional, como a Convenção Americana, seus juízes, como parte do aparelho do Estado, também estão sujeitos a ela, o que os obriga a garantir que os efeitos das disposições da Convenção não sejam prejudicados pela aplicação de leis contrárias a seu objeto e finalidade, que desde o início carecem de efeito jurídico. Em outras palavras, o Poder Judiciário deve exercer uma espécie de "controle de convencionalidade" entre as normas jurídicas nacionais aplicáveis aos casos concretos e na Convenção Americana sobre Direitos Humanos. Nesta tarefa, o Poder Judiciário deve levar em conta não só o tratado, mas também a interpretação dada pela Corte 
Interamericana, intérprete última da Convenção Americana (OEA, 2006, tradução nossa).

Assim, pode-se afirmar que, ao menos desde 2006, a Corte Interamericana tem sustentado que suas decisões são vinculantes em relação aos Estados nacionais sujeitos à sua jurisdição (VALLE, 2015, p. 371-389). Como leciona Valerio de Oliveira Mazzuoli, é dever do Estado nacional zelar pela aplicação das decisões da Corte Interamericana (2018, p. 59), apesar da forte resistência dos tribunais brasileiros (SILVA, 2010, p. 522-523). Contudo, é certo que as decisões da Corte Interamericana têm valor erga omnes, "já que o descumprimento dos tratados e das decisões dos órgãos do Pacto de São José impõe a responsabilidade internacional del Estado em face de ato de qualquer dos três poderes estatais (HITTERS, 2008, p. 131-155, tradução nossa), atraindo a sua responsabilidade.

\section{CONCLUSÕES}

Assim, a partir do exposto acima se pode, em síntese apertada, concluir que o direito nacional e as legislações internacional e comunitária protegem o trabalhador contra a despedida arbitrária e sem justa causa, cabendo ao Estado-juiz tornar eficaz essa garantia.

A decisão da Corte Interamericana de Direitos Humanos no caso Lagos del Campo vs. República do Peru consagrou o entendimento de que, nas Américas, o direito de proteção ao emprego é garantia assegurada nos textos normativos internacionais, cabendo aos Estados membros da Organização dos Estados Americanos adotarem eficazes medidas, judiciais e extrajudiciais, para sua plena eficácia.

A decisão adotada no caso Lagos del Campo vs. República do Peru vincula o Estado-juiz no Brasil. Isso porque, caso não respeitado esse precedente, com violação às normas internacionais de proteção do emprego, o Estado brasileiro poderá ser demandado a responder no plano internacional pela lesão sofrida pelo trabalhador, cuja garantia de emprego eventualmente não seja assegurada por decisão, em última instância, do Judiciário nacional.

Uma vez violado o direito de proteção ao emprego e não sendo este assegurado pelo Estado-juiz brasileiro, em demanda judicial ajuizada pelo trabalhador em face do empregador, desde que esgotado todos os recursos processuais previstos na legislação nacional, poderá o empregado lesionado demandar a República Federativa do Brasil perante a Corte Interamericana de Direitos Humanos requerendo a condenação do Estado brasileiro na reparação dos danos sofridos em face da omissão do estado-juiz brasileiro em assegurar a eficácia do direito ao emprego contra despedida arbitrária ou sem justa causa.

Uma vez condenado o Estado brasileiro perante a Corte Interamericana de Direitos Humanos, a eventual obrigação pecuniária poderá ser objeto de execução judicial perante a Vara da Justiça Federal, não havendo necessidade da prévia homologação da sentença internacional.

\section{REFERÊNCIAS}

ABRANTES, José João. O direito do trabalho e a Constituição. In: Estudos do direito do trabalho. Lisboa: AAFDL, 1991. ISBN 978-97-262-9218-0.

ALARCÓN CARACUEL, Manuel-Ramón. Derecho al trabajo, libertad profesional y deber de trabajar. Revista de Política Social, Madrid, CES, n. 121, p. 5-39, 1979. ISSN 0034-8724.

ANNONI, Danielle (Org.). Os novos conceitos no novo direito internacional. Cidadania, democracia e direitos humanos. Rio de Janeiro: América Jurídica, 2002. 516p. ISBN 978-858798-425-8. 
ARCOS RAMÍREZ, Federico. La naturaleza del derecho al trabajo como derecho social fundamental. Cuadernos Electrónicos de Filosofia del Derecho. n. 3, 2000. Disponível em: http://www.uv.es/CEFD/3/arcos.htm. Acesso em: 26 dez. 2018.

BAUGARD, Dirk. Le droit à l'emploi. Droit Social, n. 4, Paris, Dalloz, 2014, p. 332-339. ISSN 0012-6438.

BAYLOS GRAU, Antonio. El derecho al trabajo como derecho constitucional. Cuadernos de Derecho Judicial. La protección de derechos fundamentales en el orden social. v. XXI. Madrid, CGPJ, p. 13-53, 2005. ISSN 1134-9670.

BAYLOS GRAU, Antonio. El reconocimiento constitucional del derecho del trabajo en el ordenamiento español. In: UMBERTO, Romagnoli et al. Studi in onore di Giorgio Ghezzi. v. I. Milão: CEDAM, 2005. p. 253-278. ISBN 978-88-132-6012-5.

BRASIL. Constituição da República Federativa do Brasil de 1988. Brasília. Diário Oficial da União. Brasília. 1988. Disponível em: http://www.planalto.gov.br/ccivil_03/Constituicao/Constituicao.htm. Acesso em: 03 jan. 2019.

BRASIL. Decreto Legislativo nº 61 , de 1966. Aprova a Convenção nº 122, denominada Convenção sobre Política de Emprego, adotada pela Organização Internacional do Trabalho em 9 de julho de 1964. Diário Oficial da União. Brasília. 1966. Disponível em:

http://legis.senado.leg.br/legislacao/ListaTextoSigen.action?norma=585285\&id=14237048\&idBi

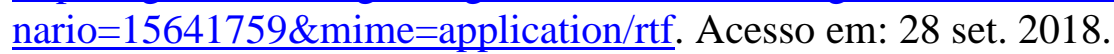

BRASIL. Decreto Legislativo nº 89, de 1998. Aprova a solicitação de reconhecimento da competência obrigatória da Corte Interamericana de Direitos Humanos em todos os casos relativos à interpretação ou aplicação da Convenção Americana de Direitos Humanos para fatos ocorridos a partir do reconhecimento, de acordo com o previsto no parágrafo primeiro do art. 62 daquele instrumento internacional. Diário Oficial da União. Brasília. 1998. Disponível em: http://www2.camara.leg.br/legin/fed/decleg/1998/decretolegislativo-89-3-dezembro-1998369634-publicacaooriginal-1-pl.html. Acesso em: 17 jan. 2019.

BRASIL. Decreto n. 2.682, de 21 de julho de 1998. Promulga a Convenção $n^{\circ} 168$ da OIT, relativa à Promoção do Emprego e à Proteção contra o Desemprego. Diário Oficial da União. Brasília. 1998. Disponível em: http://www.planalto.gov.br/ccivil_03/decreto/D2682.htm. Acesso em: 17 jan. 2019.

BRASIL. Decreto $n^{\circ}$ 66.499, de 27 de abril de 1970. Promulga a Convenção $\mathrm{n}^{\circ} 122$ sobre Política de Emprego. Diário Oficial da União. Brasília. 1970. Disponível em: http://www2.camara.leg.br/legin/fed/decret/1970-1979/decreto-66499-27-abril-1970-408230publicacaooriginal-1-pe.html. Acesso em: 17 jan. 2019.

BRASIL. Lei n.8.213, de 24 de julho de 1991. Dispõe sobre os Planos de Benefícios da Previdência Social e dá outras providências. Diário Oficial da União. Brasília. 1991. Disponível em: http://www.planalto.gov.br/ccivil_03/LEIS/L8213cons.htm. Acesso em: 28 out. 2018.

BRASIL. Supremo Tribunal Federal. ADI n. 639. Julgamento 02 de junho de 2005. Diário da Justiça. Brasília. 2005. Disponível em: 
http://redir.stf.jus.br/paginadorpub/paginador.jsp?docTP=AC\&docID=266465. Acesso em: 31 out. 2018.

CANTARO, Antonio. La costituzionalizzazione del lavoro. Il secolo lungo. In: CASADIO, Giuseppe (Org.). I diritti sociali e del lavoro nella Costituzione italiana. Roma: Hediese, 2006. p. 49-80. ISBN 978-88-230-1154-0.

CORVAL, Paulo Roberto dos Santos. Os valores sociais da livre iniciativa. Revista de Informação Legislativa, a. 43, v. 171, Brasília, p. 63-80, 2006. ISSN 0034-835X.

CRISAFULLI, Vezio. La Costituzione e le sue disposizioni di principio (Appunti preliminari sul diritto al lavoro nella Costituzione). Milão: Giuffrè, 1952. p. 145-161. ISBN 978-88-140$3275-2$.

ESPANHA. Constitución Española. 27 dez. 1978. Disponível em: https://www.boe.es/legislacion/documentos/ConstitucionCASTELLANO.pdf. Acesso em: 29 ago. 2018.

ESPANHA. Tribunal Constitucional de España. Sentencia 22/1981, de 2 de julio ECLI:ES:TC:1981:22. 1981. Disponível em: http://hj.tribunalconstitucional.es/HJ/pt/Resolucion/Show/22. Acesso em: 27 out. 2018.

FEIJÓ, Camila de Freitas. O princípio do esgotamento de recurso internos no contencioso interamericano de direitos humanos. Rio de janeiro: Lumen Juris, 2014. 227p. ISBN 978-858840-013-3.

GIUBBONI, Stefano. Il primo dei diritti sociali. Riflessioni sul diritto al lavoro tra Costituzione italiana e ordinamento europeo. I Working Papers. Centro Studi di Diritto del Lavoro Europeo “Massimo D’Antona”, n. 46/2006 (WP C.S.D.L.E. "Massimo D’Antona”. INT - 46/2006). 2006. 21p. Disponível em: http://aei.pitt.edu/13686/1/giubboni_n46\%2D2006int.pdf > Acesso em: 22 set. 2018. ISSN 1594-817X.

HITTERS, Juan Carlos. ¿Son vinculantes los pronunciamientos de la Comisión y de la Corte Interamericana de Derechos Humanos? (control de constitucionalidade y convencionalidad). Revista Iberoamericana de Derecho Procesal Constitucional. n. 10, julio-diciembre 2008, p. 131-155. México, D.F., Editorial Porrúa, ISSN 1870-8390. Disponível em: http://www.corteidh.or.cr/tablas/r25295.pdf. Acesso em: 07 fev. 2019.

HITTERS, Juan Carlos. La responsabilidad del Estado por violación de tratados internacionales. El que "rompe" (aunque sea el Estado) "paga". Estudios Constitucionales, v. 5, n. 1, junio, 2007, p. 203-222. Centro de Estudios Constitucionales de Chile, Universidad de Talca, Santiago, Chile. ISSN 0718-0195. Disponível em: https://www.redalyc.org/pdf/820/82050108.pdf. Acesso em: 11 fev. 2019.

ITÁLIA. Corte Costituzionale. Sentenza 78, 16 dicembre 1958. Deposito in cancelleria: 30 dicembre 1958. Pubblicazione in "Gazzetta Ufficiale" n. 316 del 31 dicembre 1958. Disponível em: https://www.cortecostituzionale.it/actionPronuncia.do. Acesso em: 25 jan. 2019. 
ITÁLIA. Costituzione Della Repubblica Italiana. 27 dez. 1947. Disponível em:

http://www.quirinale.it/qrnw/costituzione/pdf/costituzione.pdf. Acesso em: 29 ago. 2018.

LANDA ZAPIRAIN, Juan Pablo. Constitución y futuro del modelo español del derecho del trabajo del próximo siglo. Lan Harremanak - Revista de Relaciones Laborales, Leioa (Espanha): Universidad del País Vasco, n. 2, p. 155-184, 2000. ISSN 1575-7048. e-ISSN $2444-$ 5819.

MANCINI, Giuseppe Federico. Art. 4. In: BRANCA, Giuseppe (Dir.). Commentario della Costituzione. Principi fondamentali. Bologna/Roma: Zanichelli/Foro Italiano, 1975. p. 199-276. s/ISBN.

MAZZIOTTI, Manilo. Il diritto al lavoro. Milão: Giuffrè, 1956. 389p. s/ISBN.

MAZZUOLI, Valerio de Oliveira. O controle jurisdicional da convencionalidade das leis. 5 ed. Rio de Janeiro: Forense, 2018. ISBN 978-85-30-9819-45.

MONTOYA MELGAR, Alfredo. Ejercicio y garantias de los derechos fundamentales en matéria laboral. Revista de Política Social, Madrid: CEPC, n. 121, p. 315-345, 1979. ISSN 0034-8724.

MORTATI, Costantino. Il lavoro nella costituzione. In: GAETA, Lorenzo (Coord.). Costantino Mortati e Il lavoro nella costituzione: uma rilettura. Milão: Giuffrè, 2005. p. 7-102. ISBN 97888-141-1815-9.

ORGANIZAÇÃO DAS NAÇÕES UNIDAS (ONU). Declaração Universal dos Direitos Humanos. Resolução 217 A (III) da Assembleia Geral, de 10 de dezembro de 1948. Disponível em: http://www.onu.org.br/img/2014/09/DUDH.pdf. Acesso em: 27 out. 2018.

ORGANIZAÇÃO DAS NAÇÕES UNIDAS. Alternative approaches and ways and means within the United Nations system for improving the effective enjoyment of human rights and fundamental freedoms. Resolução 34/46. Adopted at the 76th plenary meeting, 23 Nov. 1979. In: Resolutions and decisions adopted by the General Assembly during its 34th session, 18 September 1979-7 January 1980. - A/34/46. - 1980. - p. 170-71. - (GAOR, 34th sess., Suppl. 46). Disponível em: https://digitallibrary.un.org/record/8991. Acesso em: 27 out. 2018.

ORGANIZAÇÃO DAS NAÇÕES UNIDAS. Declaração sobre o Direito ao Desenvolvimento. Revolução n. ${ }^{\circ}$ 41/128 da Assembleia Geral das Nações Unidas, de 4 de dezembro de 1986. Disponível em: http://www.direitoshumanos.usp.br/index.php/Direito-aoDesenvolvimento/declaracao-sobre-o-direito-ao-desenvolvimento.html. Acesso em: 27 out. 2018.

ORGANIZAÇÃO DAS NAÇÕES UNIDAS. Declaração sobre o Progresso e o

Desenvolvimento Social. Resolução 2.542 (XXIV) da Assembleia Geral das Nações Unidas, de 11 de dezembro de 1969. Disponível em:

http://direitoshumanos.gddc.pt/3_16/IIIPAG3_16_1.htm. Acesso em: 27 out. 2018.

ORGANIZAÇÃO DAS NAÇÕES UNIDAS. Pacto Internacional dos Direitos Econômicos, Sociais e Culturais. XXI Sessão da Assembleia-Geral das Nações Unidas, em 19 de dezembro de 1966. BRASIL. Decreto n. 591, de 6 de julho de 1992. Disponível em:

http://www.planalto.gov.br/ccivil_03/decreto/1990-1994/d0591.htm. Acesso em: 27 out. 2018. 
ORGANIZAÇÃO DOS ESTADOS AMERICANOS (OEA). Convenção Americana sobre Direitos Humanos (Assinada na Conferência Especializada Interamericana sobre Direitos Humanos), San José, Costa Rica, em 22 de novembro de 1969). Disponível em: https://www.cidh.oas.org/basicos/portugues/c.convencao_americana.htm. Acesso em: 17 jan. 2019.

ORGANIZAÇÃO DOS ESTADOS AMERICANOS (OEA). Corte Interamericana de Derechos Humanos. Informe n⿳ 95/06. Petición 92-04. Admisibilidad. Jesús Tranquilino Vélez Loor vs. Panamá. 23 de outubro de 2006. Disponível em: https://www.cidh.oas.org/annualrep/2006sp/Panama9204.sp.htm. Acesso em: 17 jan. 2019.

ORGANIZAÇÃO DOS ESTADOS AMERICANOS (OEA). Corte Interamericana de Derechos Humanos. Caso Lagos del Campo vs. Peru. Sentencia de 31 de agosto de 2017. Disponível em: http://www.corteidh.or.cr/docs/casos/articulos/seriec_340_esp.pdf. Acesso em 17 jan. 2019.

ORGANIZAÇÃO DOS ESTADOS AMERICANOS (OEA). Corte Interamericana de Derechos Humanos. Caso Almonacid Arellano y otros Vs. Chile. Sentencia de 26 de septiembre de 2006. Disponível em: http://www.corteidh.or.cr/docs/casos/articulos/seriec_154_esp.pdf. Acesso em 17 jan. 2019.

ORGANIZAÇÃO INTERNACIONAL DO TRABALHO (OIT). Constituição da Organização Internacional do Trabalho. 1946. Disponível em: https:/www.ilo.org/wcmsp5/groups/public/--americas/---ro-lima/---ilo-brasilia/documents/genericdocument/wcms_336957.pdf. Acesso em: 27 jan. 2017.

\section{ORGANIZAÇÃO INTERNACIONAL DO TRABALHO (OIT). Convenção Relativa à}

Promoção do Emprego e à Proteção contra o Desemprego n. 168. 75. a sessão, Genebra, 21 de junho de 1988. Disponível em: https://www.ilo.org/brasilia/convencoes/WCMS_236246/lang-pt/index.htm. Acesso em: 17 jan. 2019.

ORGANIZAÇÃO INTERNACIONAL DO TRABALHO (OIT). Convenção sobre Política do Emprego n. 122. 49a reunião da Conferência Internacional do Trabalho. Genebra. 1965. Disponível em: https://www.ilo.org/brasilia/convencoes/WCMS_235572/lang--pt/index.htm. Acesso em: 17 jan. 2019.

ORGANIZAÇÃO INTERNACIONAL DO TRABALHO (OIT). Declaração da Filadélfia. Declaração relativa aos fins e objetivos da Organização Internacional do Trabalho. $23^{\mathrm{a}}$ sessão, Genebra, 10 de maio de 1944. Disponível em: http://www.ilo.org/public/portugue/region/eurpro/lisbon/pdf/constitucao.pdf. Acesso em: 27 out. 2018.

PALOMEQUE LOPEZ, Manuel Carlos. Prólogo. In: SASTRE IBARRECHE, Rafael. El derecho al trabajo. Madrid: Trotta, 1996. p. 15-17. ISBN 978-84-816-4063-2.

PIOVESAN, Flávia (Coord.). Direitos humanos. v. I. Curitiba: Juruá, 2006. 736p. ISBN 978-853621-152-7. 
PORTUGAl. Constituição da República Portuguesa. 02 abr. 1976. Disponível em: http://www.parlamento.pt/Legislacao/Paginas/ConstituicaoRepublicaPortuguesa.aspx. Acesso em: 29 ago. 2018.

PROSPERETTI, Ubaldo. I principi generali del diritto del lavoro nella Costituzione. Revista Trimestrale di Diritto Pubblico, Milão: Giuffrè, n. 2, ano XX, p. 353-378, abr./jun. 1970. ISSN 2499-2526.

RESENDE, Augusto César Leite de. A executividade das sentenças da Corte Interamericana de Direitos Humanos no Brasil. Revista de direito internacional. v. 10. n. 2. 2013. p. 226-236. Centro Universitário de Brasília. SN 2236-997X (impresso) - ISSN 2237-1036 (on-line). doi: 10.5102/rdi.v10i2.2579.

SALVADOR, Jane. Implementação da sentença da Corte Interamericana no Brasil. In: PIOVESAN, Flávia (Coord.). Direitos humanos. V. I. Curitiba: Juruá, 2006. p. 643-665. 736p. ISBN 978-85-3621-152-7.

SANT'ANA, Janice Cláudia Freire. O Brasil e a execução de sentença da Corte Interamericana de Direitos Humanos. In: ANNONI, Danielle (Org.). Os novos conceitos no novo direito internacional. Cidadania, democracia e direitos humanos. Rio de Janeiro: América Jurídica, 2002. p. 253-276. 516p. ISBN 978-85-8798-425-8. SASTRE IBARRECHE, Rafael. El derecho al trabajo. Madrid: Trotta, 1996. 288p. ISBN 978-84-816-4063-2.

SILVA, Virgílio Afonso da. Integração e diálogo constitucional na América do Sul. In: BOGDANDY, Armin von. PIOVESAN, Flávia. ANTONIAZZI, Mariela Morales (orgs.). Direitos humanos, democracia e integração jurídica na América do Sul. Rio de Janeiro: Lumen Juris, 2010, p. 522-523. ISBN 978-85-375-0706-3.

SOUZA, Tercio Roberto Peixoto. A negociação coletiva e a extinção compulsória do contrato de trabalho, São Paulo: LTr, 2012. 136p. ISBN 978-85-361-1926-7.

VALLE, Rubén Hernández. La Tutela supranacional de los derechos en América. La experiencia de la Corte Interamericana. In: ROMBOLI, Roberto. ARAÚJO. Marcelo Labanca Corrêa de (orgs.). Justiça constitucional e tutela jurisdicional dos direitos fundamentais. Belo Horizonte: Arraes. 2015, p. 371-389. ISBN 978-85-238-079-6. 